\title{
Triazinane Derivatives as Possible Antimicrobial Agents
}

\author{
Bajarang Bali Lal Srivastava* \\ Department of Chemistry, School Of Physical Science, College of Natural and Mathematical science, \\ University of Dodoma, Tanzania. Post box 259
}

\begin{abstract}
Triazines (3) were synthesized by the reaction of formaldehyde with substituted benzoic hydrazides (2). Structural assignments of newly synthesized compounds are based on the analytical and spectral data.The final compound(3) were screened against various bacteria viz staphylococcus aurous(Sa) Enterococcus facalis(Ef) and Escherichia Coli(Ec) involving two strains of $(S a)$ and $(E f)$ and only one of $(E c)$ as recommended by NCCLS, Moxifloxacin and linezolid were taken as reference standard.
\end{abstract}

Keywords: Synthesis, Triazines, Hydrazides, Antibacterial activity.Moxifloxacin,linezolid.

\section{Introduction}

A number of triazines derivatives containing pharmacological groups have been synthesized possess significant antibacterial activity both in vivo and in vitro. Various triazine derivatives such as 2-amino-4morpholinyl triazine were found outstanding, more recently, some of the triazines derivatives were screened for their antiviral activity ${ }^{2}$ against Encephalomyocarditis virus (EMCV) and Japanese encephalitis virus (JEV) in vivo and in vitro. S-triazines are an important group of heterocyclic compounds. Several derivatives of heterocyclic compounds have been marketed as biologically active agents. We now wish to report our studies on the synthesis of some new S-triazines containing benzamides moiety for improved therapeutic results. The final compound(3) were screened against various bacteri viz staphylococcus aurous(Sa) Enterococcus facalis(Ef) and Escherichia Coli(Ec) involving two strains of (Sa) and (Ef) and only one of (Ec) as recommended by NCCLS, Moxifloxacin and linezolid were taken as reference standard.

\section{Material And Methods}

Melting point was determined in open capillaries and is uncorrected. IR spectra were recorded on a Perkin Elmer Spectrum RXI (4000-450 $\left.\mathrm{cm}^{-1}\right)$ spectrophotometer $\left(\mathrm{cm}^{-1}\right)$ and ${ }^{1}$ HNMR spectra in CDRI, on a Bruber DPX 300 instrument using TMS as internal standard (chemical shift in ppm.)

\section{Synthesis of Substituted Phenyl Hydrazides}

Substituted phenyl benzoate $1(0.1 \mathrm{~mol})$ was dissolved in ethanol and hydrazine hydrate $(0.15 \mathrm{~mol})$ was added to it with continuous stirring. The reaction mixture was refluxed for 5 four. Excess ethanol was distilled off. The crystals obtained were filtered and dried in vaccuo. Compounds of this category thus prepared.

\section{Synthesis Of N, N', N'-1,3,5-Triazinane-1,3,5-Triyl Tribenzamide (3a)}

Substituted benzoic hydrazides $2 \mathrm{a}(0.01 \mathrm{~mol})$ was dissolved in ethanol $(15 \mathrm{ml})$ by slow warming. The solution was cooled at room temperature and $37 \%$ formaldehyde solution $(0.025 \mathrm{~mol})$ was added to it. The resultant mixture was allowed to stand at room temperature for one $\mathrm{hr}$ a solid appeared which was filtered and washed with cold ethanol. The product was triturated with pertroleum ether. The purified product was filtered and dried in vacuum desicator. Compound of this category thus prepared along with their characterization data are listed in Table 1.

\section{Biological Activity}

All the compounds were screened against three bacteria namely staphylococcus aurus( $\mathrm{Sa})$, Enterococcus fecalis(Ef), Eschericia coli (Ec) in the Dr. Reddy Laboratory, Hyderabad. The Antibacterial activity shown in table II

\section{Result And Discussion}

Eight compounds belonging to the type N, N',N"'-1,3,5-Triazinane-1.3.5-Triyl Tribenzamide(3) were evaluated against two strains of Staphylococcus aureus, two strains of Enterococcus faecalis and one strain of Escherichia coli using the broth dilution technique as recommended by National Committee for Clinical Laboratory Standards (NCCLS). Antimicrobial activity data incorporated in Table II reveal that such compounds are not promising, chemical candidate molecules as far as antimicrobial activity is concerned since only one such compound out of eight, which were screened, displayed moderate order of activity. Thus, 
compound no. 4 having Ar = m-nitro phenyl caused inhibition of bacterial inhibition. This compound was found antibacterially active against Staphylococcus aurous and Enterococcus faecalis to a moderate degree when compared with standard drug moxifloxacin and linezolid. However, anti-bacterial activity was found to be more pronounced on comparison with linezolid. Antibacterial activity of all the compounds was determined against two strains of Staphylococcus aurous viz., methicillin susceptible Staphylococcus aurous (MSSA) and methicillin-resistant Staphylococcus aurous (MRSA); two strains of Enterococcus faecalis viz. Vancomycin susceptible Enterococcal infection and Vancomycin resistant enterococcal (VRE) infection and only one strain of Escherichia coli. Some interesting observations have become known regarding the antibacterial effect caused by compound No. 4. This compound was found more active against methicillin resistant Staphylococcus aurous (MRSA) than methicillin susceptible Staphylococcus aurous (MSSA) since MIC value was found to be 8.0 in the former case and 32 in the latter case. A compound showing activity against resistant strain of bacteria warrants more investigations since a majority of available antibiotics have developed resistance or are developing resistance. In MRSA and some penicillin resistant enterococci, an additional low affinity PBP (penicillin binding protein) is found, that is absent in sensitive strains and which can take over the function of the normal high molecular weight PBPs which have been inhibited by $\beta$-lactam action. However, the same compound was found to show the same order of antibacterial activity against both the strains of Enterococcus faecalis. It had a MIC value of 32 against both the Vancomycin susceptible Streptococcal (VSE) strain and Vancomycin resistant enterococcal (VRE) strain. The potential of this compound cannot be disputed since it is showing greater - magnitude of antibacterial activity against MRSA and equal degree of activity against VRE infection. This compound also showed antibacterial activity moderately if compared with standard linezolid $(\mathrm{MIC}=256 / 32=8)$ but not with moxifloxacin. Interestingly, the compound no. 8 having one more nitro group (Ar $=3,5$-di-nitrophenyl) was found completely inactive against both the strains of Staphylococcus aurous and Enterococcus faecalis since MIC values were $>256$. It seems quite reasonable to interpret that compound no.4 having $\mathrm{Ar}=\mathrm{m}$-nitro group finds better fit at the receptor site than the compound no.8 bearing $\mathrm{Ar}=3,5$ dinitrophenyl group. However, in order to select new chemical agents and to predict their in vitro activity against several strains of bacteria quantitative structure activity relationship (QSAR) models need to be developed. This can be done by linear discriminant analysis (LDA) and multilinear regression analyses (MLRA) by using topological indices (TI) as descriptors. In QSAR a large number of compounds of the same series having bioactivity are required but QSAR does not address the lead molecule. In the present case although eight compounds were screened for their antimicrobial activity, only one compound displayed a moderate order of activity. In order to find out a better correlation between the antimicrobial activity and the structural features, synthesis of more such compounds having additional and different substituent's not only at one position of the molecular architecture but at other positions (at least two or three) is desirable.

\section{References}

[1]. Abha Bishnoi; R Saxena., Indian Journal of Hetrocycle Chemistry; 11, 2001, 47-50.

[2]. K Newman; U. S. 4006, 159, Chem. Abs 1979, 86, 189955,

[3]. J. S Smith.; P. A Yager. and M G Bayes, Amer J vet Bes. 41,1980 , 1833; Chem Abs 93, 1980, 236755

[4]. F.G Mam. and B. S.Saunders. Practical Organic Chemistry page 305, English Language Book society $4^{\text {th }}$ edition (1970)

[5]. V. K. Pandey.; S .Yadav; M N .Joshi and S. K. Bajpai, Antivual activity of s-triazine, Buel Mem, 26, 2000, 4851

[6]. srirupa Sen and B.B.L.,Srivastav, synthesis of some new trizinane derivatives,In.J.Heterocyclic chem.,Vol.14.200,269-270

Table I

\begin{tabular}{|l|l|l|l|l|l|l|l|l|}
\hline Compd. & R & M. P. oC & Yield\% & Mol. Formula & \multicolumn{2}{l}{$\begin{array}{l}\text { Mol. } \\
\text { Wt. }\end{array}$} & \multicolumn{2}{l|}{$\begin{array}{l}\text { Elemental Analysis found } \\
\text { (Calculated) }\end{array}$} \\
\cline { 5 - 9 } & & & & & & & & \\
$\mathrm{C}$ & & & & & & $\mathrm{H}$ \\
\hline $3 \mathrm{a}$ & $\mathrm{H}$ & 135 & 80 & $\mathrm{C}_{24} \mathrm{H}_{24} \mathrm{~N}_{6} \mathrm{O}_{3}$ & 444.49 & $64.82(64.85)$ & $5.47(5.44)$ & $18.92(18.91)$ \\
\hline $3 \mathrm{~b}$ & $\mathrm{p}-\mathrm{cl}$ & 145 & 75 & $\mathrm{C}_{24} \mathrm{H}_{21} \mathrm{~N}_{6} \mathrm{O}_{3} \mathrm{Cl}_{3}$ & 547.82 & $52.65(52.62)$ & $3.82(3.86)$ & $15.30(15.34)$ \\
\hline $3 \mathrm{e}$ & $\mathrm{p}-\mathrm{NH}_{2}$ & 125 & 70 & $\mathrm{C}_{27} \mathrm{H}_{32} \mathrm{~N}_{4} \mathrm{O}_{1}$ & 489.53 & $59.62(58.8)$ & $6.25(5.56)$ & $25.1(25.75)$ \\
\hline $3 \mathrm{~d}$ & $\mathrm{~m}-\mathrm{NH}_{2}$ & 138 & 82 & $\mathrm{C}_{24} \mathrm{H}_{24} \mathrm{~N}_{4} \mathrm{O}_{4}$ & 489.53 & $57.71(58.8)$ & $5.63(5.56)$ & $25.72(25.75)$ \\
\hline $3 \mathrm{e}$ & $\mathrm{m}-\mathrm{NO}_{2}$ & 136 & 80 & $\mathrm{C}_{24} \mathrm{H}_{21} \mathrm{~N}_{9} \mathrm{O}_{9}$ & 579.48 & $49.71(49.74)$ & $3.63(3.65)$ & $21.72(21.75)$ \\
\hline $3 \mathrm{f}$ & $3,5-\mathrm{diNO}_{2}$ & 148 & 85 & $\mathrm{C}_{24} \mathrm{H}_{18} \mathrm{~N}_{12} \mathrm{O}_{15}$ & 714.47 & $40.32(40.35)$ & $2.563(2.54)$ & $23.50(23.53)$ \\
\hline $3 \mathrm{~g}$ & $\mathrm{p}-\mathrm{OH}$ & 150 & 65 & $\mathrm{C}_{24} \mathrm{H}_{24} \mathrm{~N}_{6} \mathrm{O}_{6}$ & 492.48 & $56.50(58.53)$ & $4.88(4.91)$ & $17.10(17.06)$ \\
\hline $3 \mathrm{~h}$ & $-\mathrm{OCH}$ & 153 & 60 & $\mathrm{C}_{27} \mathrm{H}_{30} \mathrm{~N}_{6} \mathrm{O}_{6}$ & 534.56 & $60.61(60.66)$ & $5.63(5.63)$ & $15.68(15.72)$ \\
\hline
\end{tabular}


Triazinane Derivatives As Possible Antmicrobial Agents

Table II

\begin{tabular}{|c|c|c|c|c|c|c|}
\hline \multirow[t]{3}{*}{ Compound No. } & \multirow[t]{3}{*}{ Ar } & \multicolumn{5}{|c|}{ Minimum Inhibitory Concentration (MIC) in $\mu \mathrm{g} / \mathrm{ml}$} \\
\hline & & \multicolumn{2}{|c|}{ Sa } & \multicolumn{2}{|c|}{ Ef } & \multirow{2}{*}{$\begin{array}{l}\text { Ec } \\
\text { DRCC018 }\end{array}$} \\
\hline & & $\begin{array}{l}\text { DRCC035 } \\
\text { MSSA } \\
\end{array}$ & $\begin{array}{l}\text { DRCC018 } \\
\text { MRSA } \\
\end{array}$ & DRCC034 VSE & DRCC153 VRE & \\
\hline 1 & & $>256$ & 128 & $>256$ & $>256$ & $>256$ \\
\hline 2 & & 256 & 128 & $>256$ & $>256$ & $>256$ \\
\hline 3 & & $>256$ & 256 & $>256$ & $>256$ & $>256$ \\
\hline 4 & & 32 & 8 & 32 & 32 & $>256$ \\
\hline 5 & & $>256$ & 256 & $>256$ & $>256$ & $>256$ \\
\hline 6 & & $>256$ & $>256$ & $>256$ & $>256$ & $>256$ \\
\hline 7 & & $>256$ & $>256$ & $>256$ & $>256$ & $>256$ \\
\hline 8 & $\mathrm{O}_{2} \mathrm{~N}$ & 256 & $>256$ & $>256$ & $>256$ & $>256$ \\
\hline & Moxifloxacin & 0.6 & 0.6 & 0.25 & 0.25 & 0.03 \\
\hline & Linezolid & $\begin{array}{l}2.0 \\
(2.4)\end{array}$ & $\begin{array}{l}1.0 \\
(1.2)\end{array}$ & $\begin{array}{l}2.0 \\
(2.4)\end{array}$ & $\begin{array}{l}1.0 \\
(2.4)\end{array}$ & $>32$ \\
\hline
\end{tabular}

$\mathrm{Sa}=$ Staphylococcus aureus $; \mathrm{Ef}=$ Enterococcus faecalis $; \mathrm{Ec}=$ Escherichia coli 